\title{
Universal access and human rights
}

Population Council

Follow this and additional works at: https://knowledgecommons.popcouncil.org/ series_newsletters_momentum How does access to this work benefit you? Let us know!

\section{Recommended Citation}

"Universal access and human rights," Momentum newsletter. New York: Population Council, 2010. 

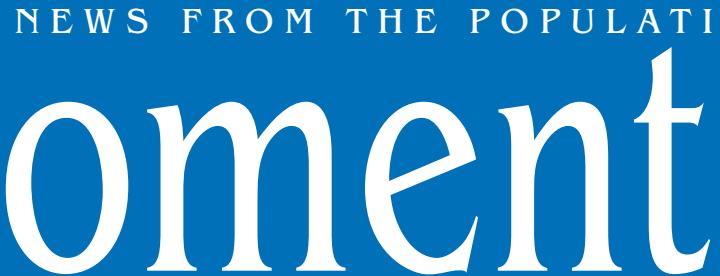

C O U N C I L


NOVEMBER 2010

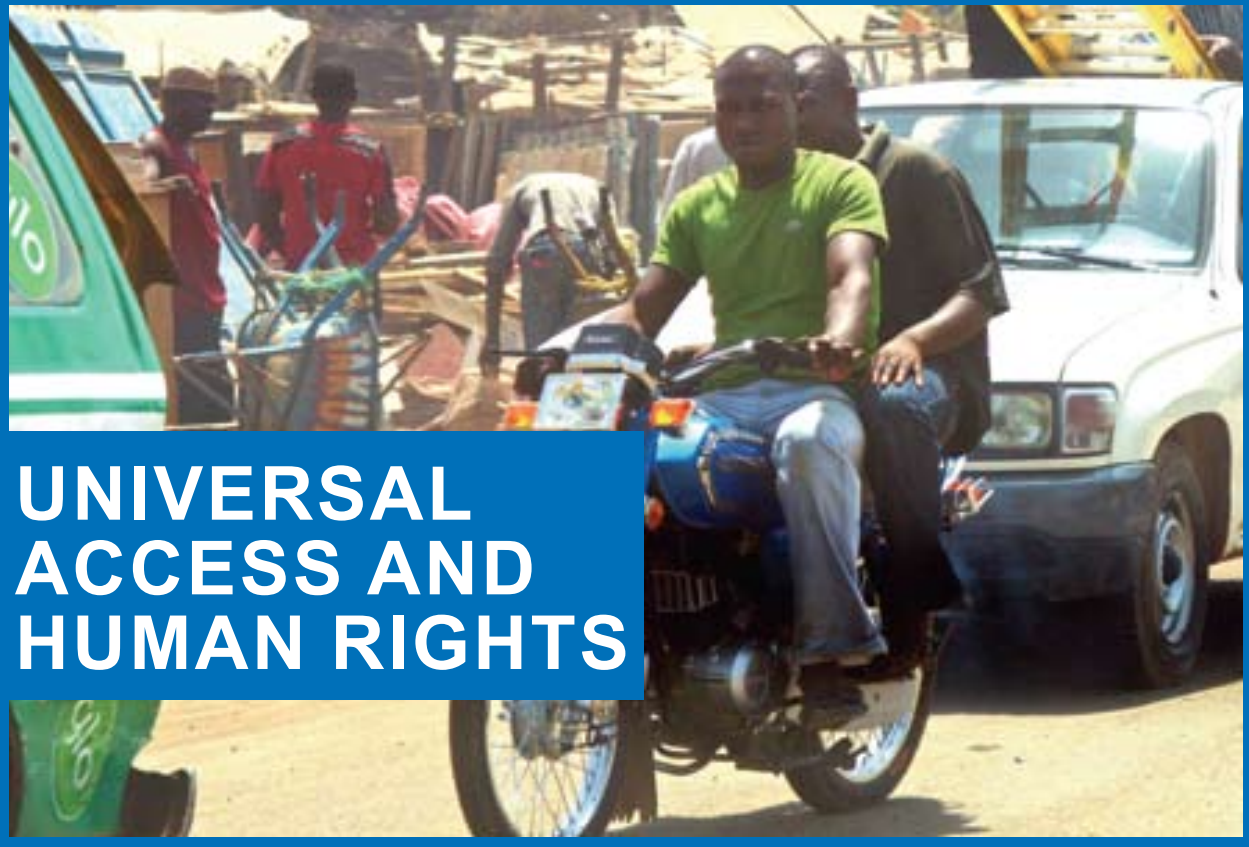

The Men's Health Network Nigeria focuses on the HIV prevention needs of high-risk men.

\section{IN THIS ISSUE:}

POPULATION COUNCIL PRESIDENT DISCUSSES THE GLOBAL HIV EPIDEMIC

PREVENTING HIV AMONG INJECTING DRUG USERS

REACHING MEN WHO HAVE SEX WITH MEN

ADAPTING TRADITIONS TO REDUCE YOUNG PEOPLE'S RISK OF HIV

INCREASING WOMEN'S CONTROL OVER HIV PREVENTION

PROFILES: MELISSA ROBBIANI, COUNCIL RESEARCHER, AND COUNCIL DONORS TAMMY ALLEN AND DAN GROPPER 


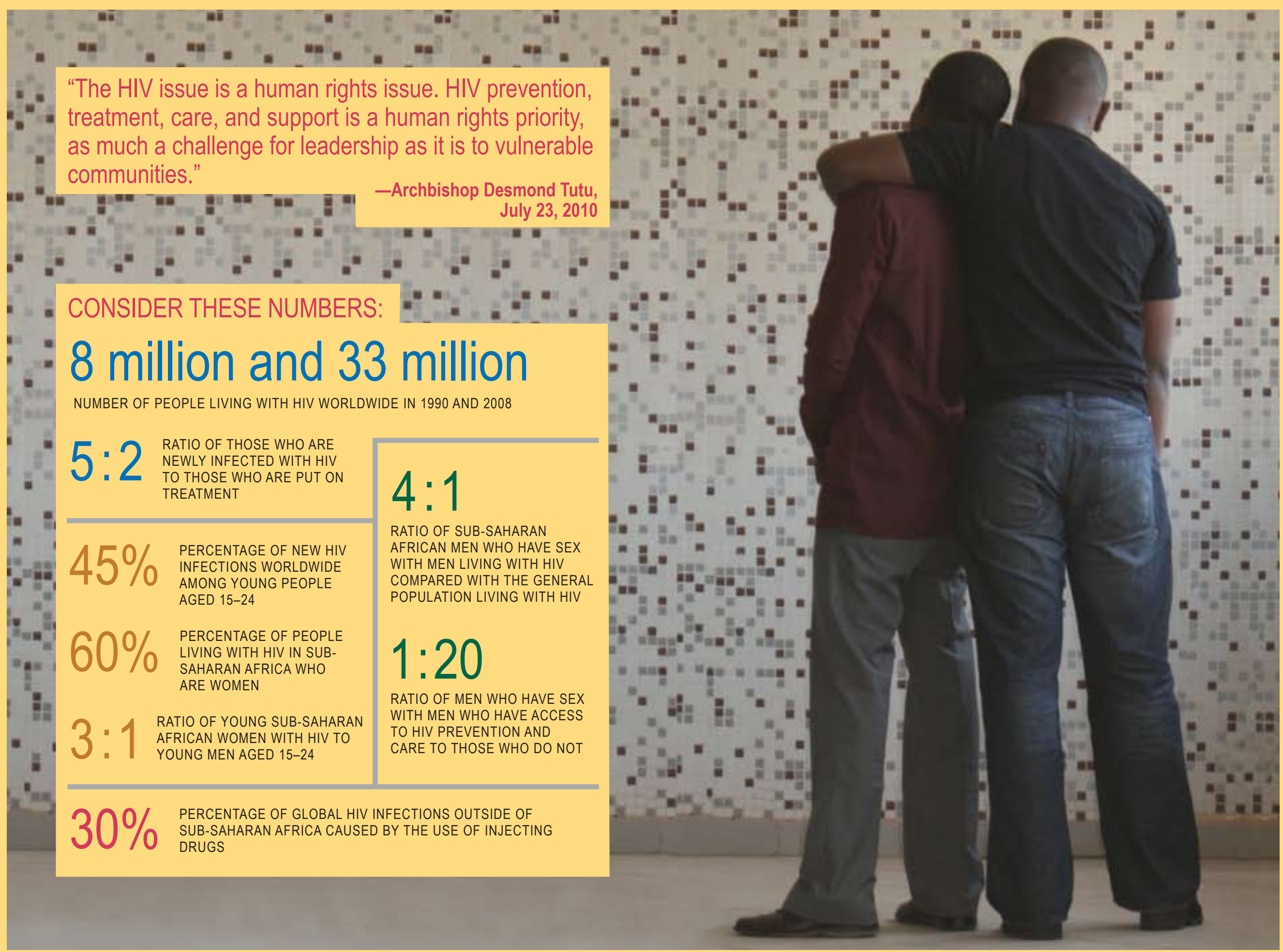






Despite tremendous progress in combating the HIV pandemic, 7,000 people become infected with HIV daily. Every December 1 on World AIDS Day, we come together as individuals, organizations, and political leaders to recommit to the global targets for HIV and AIDS prevention, care, and treatment. This year's World AIDS Day theme, "Universal Access and Human Rights," encourages us to deepen understanding, develop partnerships, and challenge discriminatory practices that stand in the way of access for all to HIV prevention, care, and support. The Population Council grounds its HIV and AIDS research in this rights-based framework.

Sadly, those most vulnerable to HIV often have the least access to lifesaving HIV prevention methods and services. For example, men who have sex with men
(MSM) in sub-Saharan Africa, whose HIV risk is two to four times that of the general population, avoid seeking or are denied HIV services because of the stigmatization, discrimination, and criminalization surrounding homosexual behavior. Similarly, young people, who account for 45 percent of new HIV infections, lack adequate information and the means to protect themselves against HIV because of fears and taboos surrounding adolescent sexuality.

Failure to reach these and other at-risk populations violates their human rights All those at risk deserve the chance to make informed and confidential decisions about health, to receive services free from discrimination, and to access the care needed to live a healthful life. We will not reverse the spread of this epidemic until AIDS responses reach these overlooked populations.
With your support, the Population Council is making important contributions to the global fight against HIV. Our comprehensive strategies include:

- Calling attention to the risks and needs of marginalized populations vulnerable to HIV.

- Implementing and evaluating innovative programs to provide even the hardest-to-reach populations with health and education services tailored to their specific needs.

- Developing microbicides to increase HIV-prevention options for those most in need.

- Influencing policy to ensure that marginalized populations are included in national HIV programs.

This issue of Momentum illustrates ways in which the Council is increasing access to HIV prevention and services for hard- to-reach populations, including injecting drug users in India (page 4), MSM in Nigeria (p. 6), and adolescents in Kenya (p. 8). To develop a much-needed femaleinitiated method to prevent transmission of HIV, Council staff are formulating and testing microbicides (p. 10). Melissa Robbiani, who leads the Council's biomedical research on HIV, describes the essential role that basic research plays in making a large-scale impact in HIV prevention. You will also read why two of our supporters, Tammy Allen and Dan Gropper, give to the Council (p. 12).

Your contribution enables the Council to expand our reach, so that we will soon see the day when there will be universal access to the information, services, and strategies to prevent HIV. 
In India, HIV prevalence among injecting drug users is 10 percent nationally and 22 percent in Delhi.

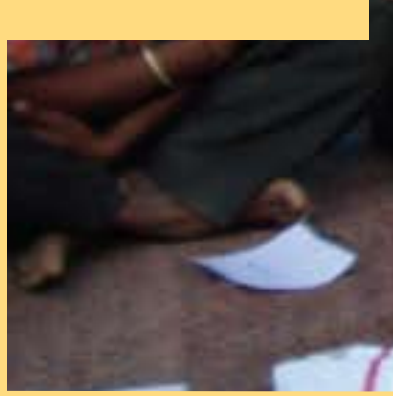

THE PROBLEM India has one of the largest populations of injecting drug users (IDUs) in the world, estimated at 1.1 million nationally and 35,000 in Delhi. People who inject drugs are particularly at high risk of HIV from sharing syringes and other injection equipment. Many studies have reported IDUs to be not only sexually active, but to have risky sexual practices. When IDUs become infected with HIV, they imperil their needle-sharing partners, sexual partners, and future children. Yet HIV prevention services for this vulnerable population are scant and fail to serve a sizable proportion of IDUs.
Ignoring the needs of IDUs and their injecting and sexual partners undermines efforts to eradicate HIV in India.

THE PROGRESS Research by the Population Council characterized the risk behaviors of IDUs in Delhi and identified appropriate intervention strategies, such as outreach to and services for IDUs living on the street-a homeless and unstable population. Through this preliminary work, we established a strong institutional relationship with a service delivery partner, Sahara, and helped to guide Sahara's programming. Our research also revealed that IDUs have frequent interactions with other IDUs or sex partners or both. IDUs can potentially have an important role to play in recruiting their peers for services.

THE IMPACT The Council has launched AVHI (Averting HIV infections among IDUs), a large-scale project to increase the reach and comprehensiveness of HIV prevention and other harmreduction services, thereby reducing risky behaviors among IDUs in Delhi. To ad-
THE COUNCIL HAS LAUNCHED

AVHI TO INCREASE THE REACH AND COMPREHENSIVENESS OF HIV PREVENTION AND OTHER HARMREDUCTION SERVICES, THEREBY REDUCING RISKY BEHAVIORS AMONG IDUS IN DELHI. 


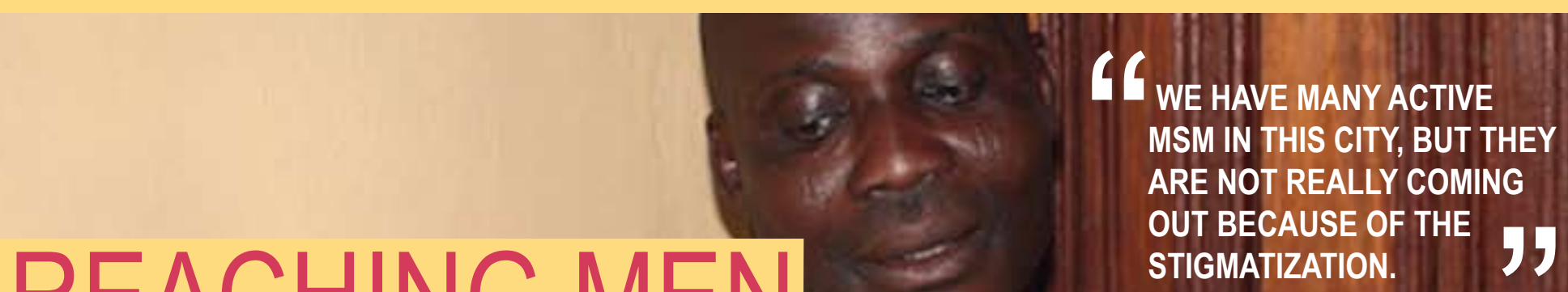
REACHING MEN WHO HAVE SEX WITH MEN

In Nigeria, and in many other countries in Africa, MSM face stigma, discrimination, and even criminalization of their behavior.

THE PROBLEM Fourteen percent of men who have sex with men (MSM) in Nigeria are infected with HIV, compared to about 3.2 percent of the general population of men. MSM are highly vulnerable to HIV both because unprotected anal sex is riskier than other kinds of unprotected sex, and because they have little access to HIV prevention services that address their needs for information, condoms, lubricants and care for sexually transmitted infections. Health programs are generally not interested in addressing, or even recognizing, the needs of MSM, and nearly all HIV prevention focuses on heterosexual transmission of HIV. Where services exist, many MSM still shun health care and counseling that might reduce their risk of HIV infection because of the stigma attached to male-tomale sexual behavior.

THE PROGRESS The Popula6



Men's Health Network Nigeria (MHNN), the first national comprehensive program to focus on HIV prevention and other health needs of MSM and other high-risk men such as drug users, transport workers, and uniformed personnel. The Network aims to improve MSM's knowledge of HIV transmission and signs of sexually transmitted infections, use of condoms, and access to appropriate and respectful health care. It mobilizes leaders within the MSM community to deliver HIV prevention messages to their peers and to make referrals to MHNN clinical service providers, who have received training in gender and sexual orientation sensitivity and diversity. MSM are also engaged through virtual social networks, including text-messaging services, hotlines, and online chat rooms. tion Council conceived and launched the (1)

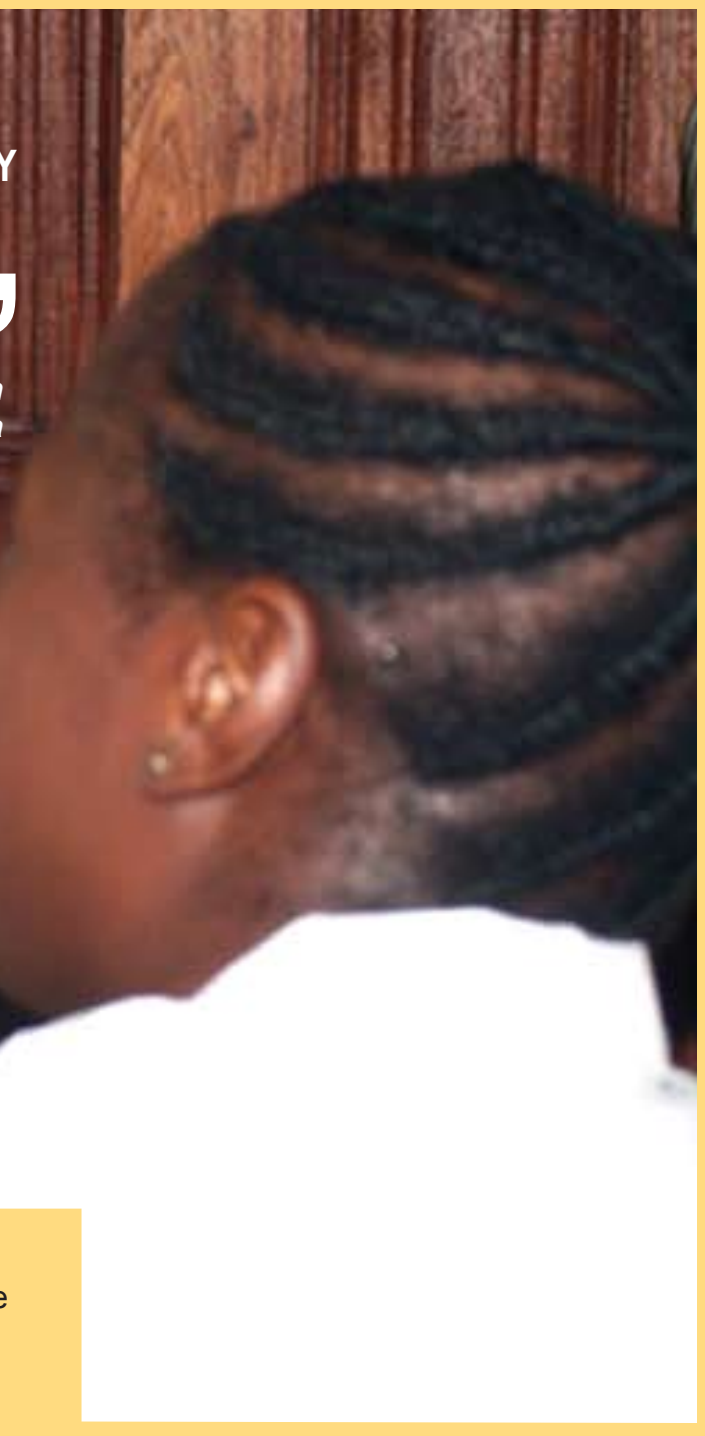
enrolled 10 health care facilities in three states; trained 30 health care providers, including doctors and counselors, in "MSM-friendly" service delivery; and catalyzed the development of a Nigerianowned peer education training manual for MSM and injecting drug users.

THE IMPACT The Council has brought the issue of MSM to the forefront in Nigeria and other African countries such as Kenya and Senegal, advocating for their health needs to policymakers and piloting and evaluating programs to deliver services for this overlooked population. MHNN has reached 21,000 high-risk men with HIV prevention messages and tested nearly 7,000 men for HIV. With our partners, the project will continue to expand to at least two additional states, men by July 2011, and has the potential to become the largest service delivery program for MSM in sub-Saharan Africa.

DONORS AND PARTNERS us Centers for Disease Control and Prevention, Ford Foundation, Society for Family Health/DFID, The Independent Society for Family Health/DFID, The Independent
Project for Equal Rights (TIER), Male Attitudes Network (MAN), Green Trust, Kind Hearts, Freedom Foundation, Association of Reproductive and Family Health (ARFH), Centre for the Right to Health (CRH), and African Health Project (AHP). aiming to reach an additional 13,600 


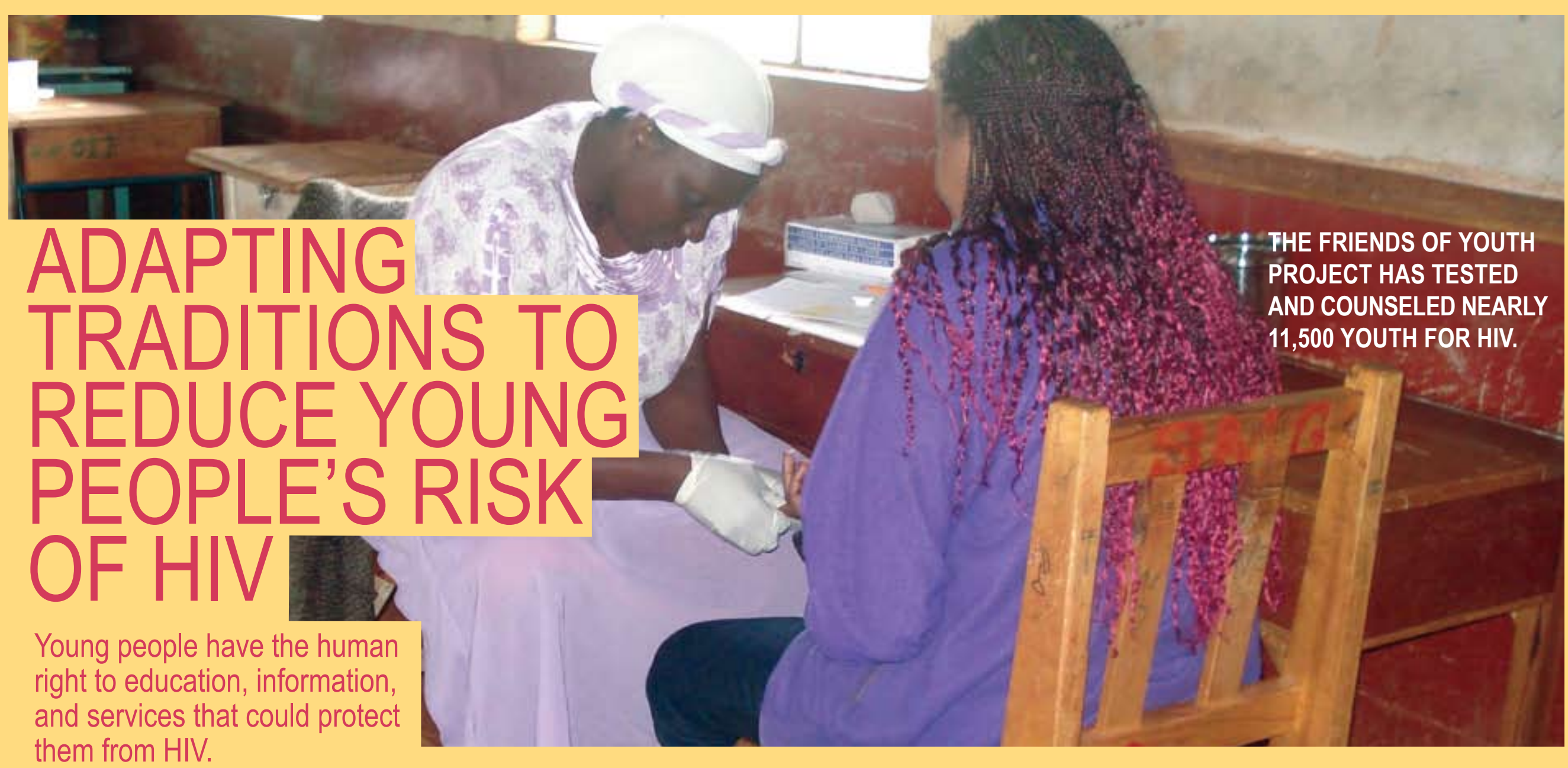
them from HIV.

THE PROBLEM Youth in Kenya, as in many countries, face significant threats to their health and well-being. These include HIV and AIDS, high rates of sexually transmitted infections, and unintended pregnancies. Sexual and reproductive health information and services, including how to prevent acquisition of HIV, are often withheld from adolescents because of the unwillingness to recognize that teens are sexually active and pervasive beliefs that education about sex and contraceptives leads to promiscuity. The consequences of ignoring adolescents' need for accurate information and services are severe. young people between the ages of 15 and 24 are living with HIV. Nearly 80 percent of those youth live in sub-Saharan Africa. Young women are the most at-risk. In Kenya, young women are four times more likely to be HIV-infected than men (6.1 percent compared to 1.5 percent).

THE PROGRESS The Population Council initiated the Friends of Youth project in Kenya to promote behaviors that decrease the risk of HIV acquisition among youth and provide youthfriendly HIV counseling, testing, and support services. The project draws on traditional practices where uncles and aunts provide youth with reproductive health information and guidance as they make the transition from adolescence to adulthood. Friends of Youth are trusted and respected adults nominated by local communities and trained to teach young people about HIV and AIDS, reproductive health, and life skills. They also work with adults who interact with young people, especially teachers, parents, and church leaders, to give them the skills to talk to young people about HIV and AIDS and positive and healthy lifestyles. Finally, Friends of Youth refer youth to service providers using coupons, which entitle them to STI services at a subsidized cost.

THE IMPACT The Friends of Youth project demonstrated how indigenous practices in Africa can be adapted to reduce young people's risk of HIV. Initial results indicated that participating girls are more likely to have fewer sexual partners and boys are significantly more likely to use condoms. The project has been scaled up rapidly since its inception to include 250 active Friends of Youth operating in the towns of Nyeri, Nyahururu, Thika, Nairobi, and Embu, reaching over 80,000 young people annually. The project includes 37 "youthfriendly" service providers and 60 HIV counseling and testing counselors and supervisors.

DONORS AND PARTNERS Us Centers for Disease Control and Prevention, Family Health Options Kenya 
INCREASING WOMEN'S CONTROL OVER HIV PREVENTION

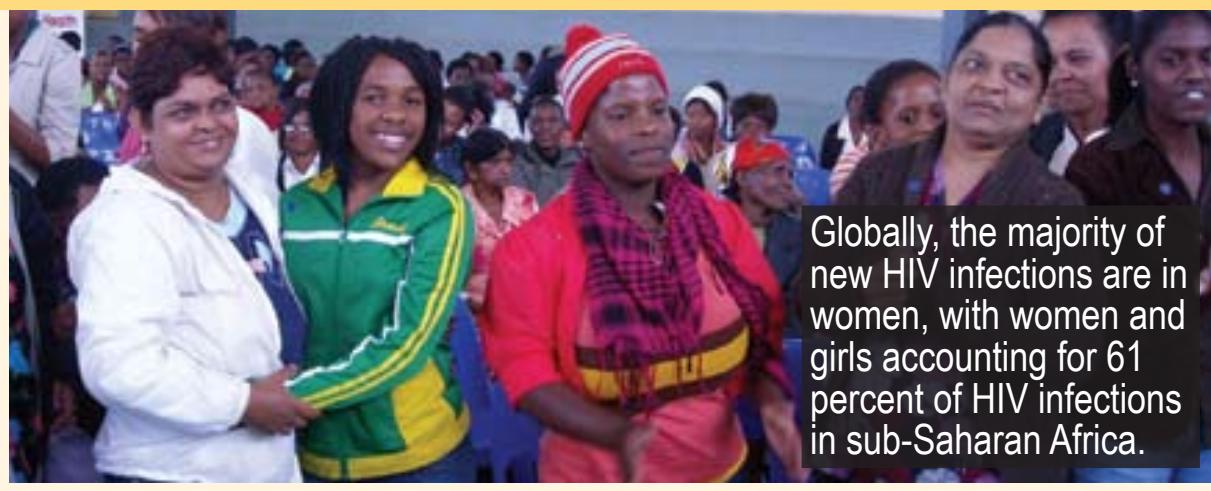

THE PROBLEM Imagine this scenario: a nurse advises a young South African woman living in a community where more than one-third of her peers are infected with HIV to use condoms to protect herself from infection. Yet when she returns home, her partner refuses, insisting that by asking him to use a condom, she must be unfaithful or does not trust him to be faithful. Unfortunately, this scenario is the reality for many women. Many women do not have the social or economic power to insist on condom use and fidelity or to abandon male partners who put them at risk. Women everywhere need options to protect themselves from HIV. A microbicide is a female-initiated method for reducing male-to-female transmission of HIV during sexual intercourse. Because a microbicide does not require a partner's cooperation, it provides women greater power to protect themselves against HIV.

THE PROGRESS The Population Council has been at the forefront of microbicide development for more than 20 years. The Council conceived, developed, and advanced through clinical trials its first microbicide product, Carraguard ${ }^{\circledR}$, a gel containing carrageenan. Carraguard was the first microbicide candidate to complete a Phase 3 efficacy clinical trial among a general population of women as planned and with no safety concerns. Although Carraguard was not found to be effective in preventing HIV, it was acceptable to women, and its extensive safety profile has supported using carrageenan-based gels as the vehicle for our products.

THE IMPACT To increase choices for women, the Council is developing different microbicide formulations and delivery systems to prevent HIV and other sexually transmitted infections. These delivery systems include gels, vaginal rings that can remain in place for several months at a time, and combined microbicide/contraceptive rings. Clinical testing of these new formulations will begin in 2011. Complementary behavioral and social science research seeks to improve conduct of microbicide clinical studies and product use.

DONORS AND PARTNERS USAID, NIH, Government of Sweden, International Partnership for Microbicides, Microbicides Trial Network, Albert Einstein College of Medicine
MELISSA ROBBIANI, Ph.D.

\section{COUNCIL RESEARCHER}

How did you become interested in biomedical research?

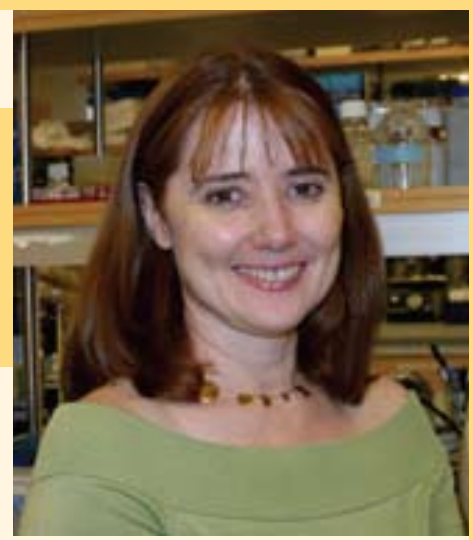

Even in high school I was interested in how the body responds to different organisms. In 1992, I completed my $\mathrm{PhD}$ in immunology in Australia and moved to America at the time when HIV research had been heating up for a few years. I took a position at Rockefeller University where I studied how immune cells interact with HIV and how that led to infection and transmission. While at Rockefeller, I worked with Council researchers on microbicides and joined the Council in 2001. What appealed to me about the Council was the overall goal of getting something out there in the developing world to prevent HIV rather than just doing basic cell research, which is fun, but you can lose sight of the big picture just looking at cells and viruses all day.

What are the greatest challenges to finding a vaccine or HIV-prevention methods?

The biggest challenge is understanding what happens in the earliest moments when the virus is being transmitted and how it establishes infection. While we know a lot, we still don't know all the details of exactly what the virus needs to establish infection and what the body tries to do to combat it. If we know these details, we will be able to design better strategies to prevent infection, whether it's in the form of a microbicide or a vaccine.
What has been the most exciting breakthrough in your career in the Council?

There have been many breakthroughs In basic research, there has been a lot of progress in understanding the early events of HIV transmission and how the virus interacts with cells. I think the most exciting breakthrough was completing the Phase 3 clinical trial of our microbicide candidate, Carraguard ${ }^{\circledR}$. While it wasn't shown to be effective against HIV concluding the first Phase 3 trial in the microbicide field was a huge step. We broke the ground for others to do these studies in the field.

What do you think the Population Council can contribute to HIV research?

We have a lot of promise on the basic research side and in the products in the pipeline. We can use our experience from Carraguard ${ }^{\circledR}$ to help move these products forward. Another big strength is our complementary behavioral research, which helps us figure out how to deliver products to people and how to conduct the best clinical trials possible. Doing the trials properly will help us get reliable results. 
TAMMY ALLEN AND DAN GROPPER COUNCIL DONORS

My husband, Dan, and I support the Population Council because I previously worked as Special Assistant to the President at the Council. We believe in the Council's innovative approaches to reducing suffering and improving health, particularly among vulnerable populations in developing countries.

As a staff member, I worked in the New York headquarters and had the opportunity to visit Council projects in Egypt, Ghana, Kenya, and Mexico. I learned first-hand how the Council's projects effectively address the most pressing needs of developing countries. For example, while in Navrongo, Ghana, I saw how the Population Council's partnership with the Ghana Health Service succeeded in saving lives and improving access to rural health services-not just in Navrongo but across much of Ghana-by changing the focus from clinical care to high-quality health services at community and doorstep locations.

We recognize how critical it is for the Council to sustain a strong local presence through its 17 country offices, as well as maintain a corps of leading scientists and scholars from around the world. Most meaningful to us is the Council's ability to hire and train developingcountry scholars, build local capacity, and respond to emerging local needsoften addressing complex issues and establishing programs within isolated, hard-to-reach communities. In particular, the 2006 opening of the Council's office in

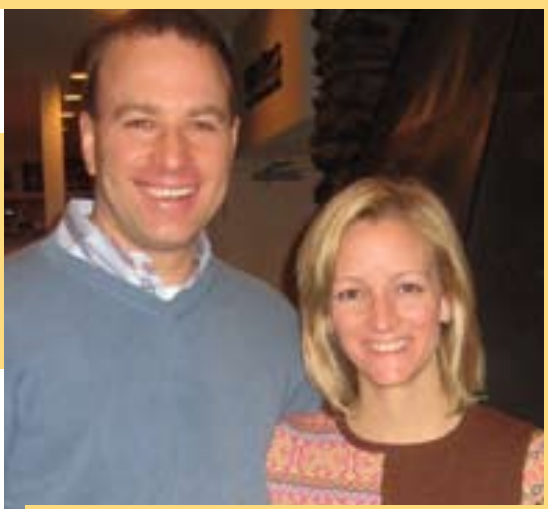

WHY WE GIVE TO THE POPULATION COUNCIL

Khartoum was momentous in light of the inextricable conflict and health problems in Sudan. The Council is working with local partners to strengthen reproductive healthcare service delivery for internally displaced women and to improve the quality of education for girls living in refugee camps-a setting where other research organizations might not venture. Without the Population Council, these Sudanese women and girls likely would face a bleak future.

Today, Dan and I stay connected to the Population Council because we strongly believe in the value of its work and in the importance of global health initiatives. I now work at AmeriCares, an international disaster relief and humanitarian aid organization, which collaborates with the Council, for instance to bring medications as well as health and social service programs to adolescent girls in Haiti following the recent earthquake.

We know our donations to the Population Council are used wisely, responsibly, and globally. We encourage you to join us in supporting the Council, as it stands at the forefront of evidence-based, creative solutions to some of the most challenging issues confronting the world today.
As we come together on World AIDS Day on December 1, we call attention to the urgent need for universal access to essential information, services, and strategies to prevent HIV.

\section{ACCESS TO HIV PREVENTION, TREATMENT, CARE, AND SUPPORT IS A HUMAN RIGHT.}

Providing accurate information and ensuring equal access to HIV services reduces the risk of HIV infection of vulnerable groups such as women, young people, injecting drug users, and men who have sex with men. We cannot neglect these populations if we are to arrest HIV transmission and repair the devastation to the families and communities affected by AIDS.

Your involvement with the Population Council allows us to help those who are most at risk by creating new HIV prevention options, linking them to the full range of HIV services, and fighting for the right of people with HIV to live free from discrimination. Through biomedical research, we advance the development of microbicides that can be used by women to prevent HIV infection. We use study results to raise awareness about the rights and needs of vulnerable populations, to improve service delivery, and to effect positive change with health care managers and national policymakers.

With your help, the Population Council has made valuable progress in increasing access to HIV and AIDS services, yet greater commitment and support are needed to achieve universal access. Please give to the Population Council so these highly vulnerable women, men, and adolescents have a chance for a healthy and productive HIV-free life. Thank you. 

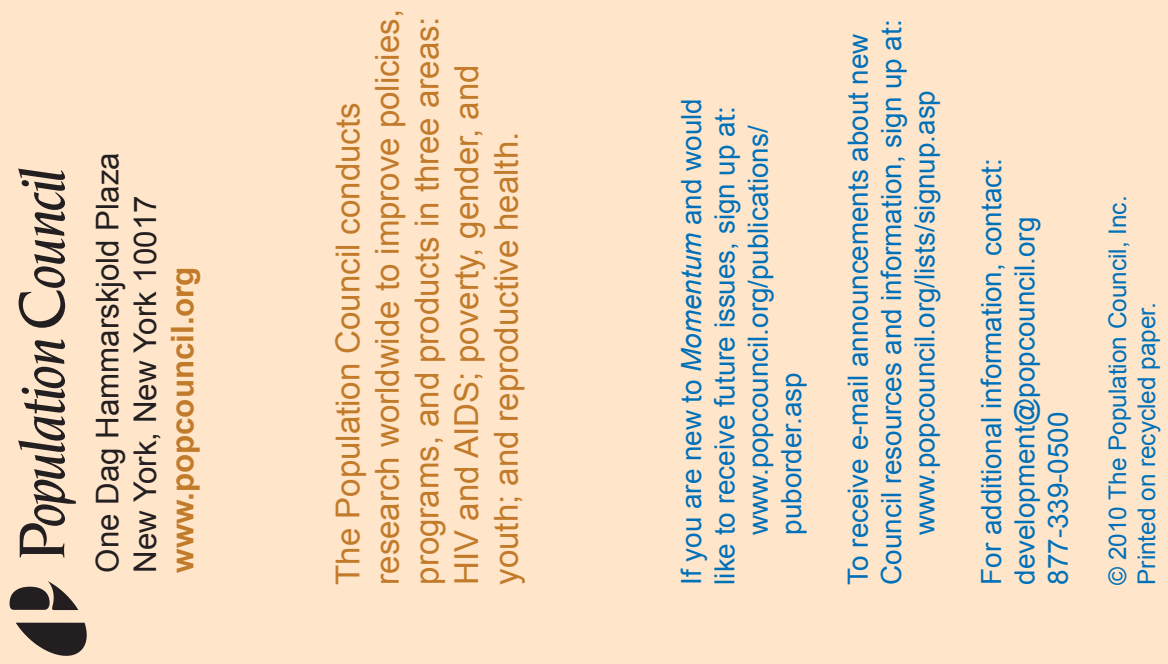